\title{
CONCEITO CLÁSSICO E POST-CLÁSSICO DO JUS NATURALE E DO JUS GENTIUM
}

\author{
Ernani Guarita Cartexo \\ Professor de Direito Romano da Faculdade de \\ Direito da Universidade do Paraná
}

A propósito da compreensão do jus privatum, as fontes romanas exibem tal vacilação de conceitos, que, por via dessa desconformidade teórica, foram os intérpretes, que versaram a interessante questão, levados a se situarem em campos diversos, senão antagônicos, em correspondência às posições, que entendem fixadas pela opinião dos jurisprudentes romanos.

Que a sistemática romana é imprecisa a êsse respeito, provam-no as Institutas, ainda que se possa mais culpar a ciência dos juristas da decadência que a doutrina dos escritores compilados. Numa óbra de síntese, elaborada em quatro resumidos livros, e destinada a conter apenas os rudimentos de tôda a ciência jurídica (1), incluída nos cincoentas livros de Digesto, haveriam de surgir os contrastes de opinião, que seriam, agora, da própria óbra e não dos autores, que se citavam, sem menção do seu nome.

Com efeito, como veremos mais adiante, a doutrina das Institutas acolhe a divisão bipartida do direito privado, de

(1) "... totius legitimae scientiae prima elementa" (Const. Imperatoriam majestatem, \& 4). 
acôrdo com Gaio, ao lado da divisão tripartida, conforme a exexpôs Ulpiano. Inclui a noção de um jus gentium, que flutua contraditòriamente na indeterminação conceitual do seu alcance, ora identificado com o jus naturale até os limites extremos de uma perfeita sinonimia vocabular, ora divergente dêle, não só nas suas origens ou na compreensão do objeto de suas incidências peculiares, como até nas abertas antinomias, em que se contradizem, a ponto de um significar a negação do outro, no antagonismo das instituições, que derivam de um e outro.

Dessa indeterminação de conceitos teóricos não se furtou o Digesto, se bem que o processus da codificação dos jura melhor marcasse as falhas da presumida unidade doutrinária da compilação, em que até as próprias contradições seriam sempre conciliáveis (2), já que a fragmentação propositada dos textos transcritos contribuia para dificultar a constatação das antinomias resultantes da opinião dos autores citados.

Em face da doutrina do Digesto, os critérios usados na sub-divisão do jus privatum admitem uma tripla classificação, de conformidade com a nomenclatura de que usam os jurisconsultos mais representativos de cada qual dessas correntes:

1) - a de Ulpiano, segundo a qual o direito privado se divide em jus naturale, jus gentium e jus civile;

2) - a de Gaio, para quem o jus privatum compreende o jus gentium e o jus civile;

3) - a de Paulo, que o apresenta dividido em jus naturale e jus civile.

Para evidenciar, nas suas afinidades e antagonismos, a correlação dessas classificações, é de se notar que tôdas as teorias são concordes na conceituação dada ao jus civile, que é, como se viu, a parte do direito privado identicamente adotado em tôdas elas.

(2) "Contrarium aliquid, in hoc codice positum, nullum sibi locum vindicabit, si quis subtile animo diversitatis rationes excutiet" (Const. Tanta circa, § 15). 
Segundo Ulpiano, o direito civil é aquele que nem se afasta de todo do direito natural ou das gentes nem de todo se subordina a êle; assim quando acrescentamos ou tiramos alguma cousa ao direito comum, fazemos um direito próprio, isto é, civil (3).

No conceito de Gaio, todos os povos, que se regem por leis e costumes, usam de um direito, que lhes é próprio em parte e é em parte comum a todos os homens; aquele, que cada povo constituiu para si, é o direito próprio da cidade e se chama direito civil, como direito peculiar dela mesma (4).

Paulo entende que o direito é tomado em várias acepções, e, numa delas, é aquele que, em cada cidade, é útil a todos ou à maior parte, e tal é o direito civil (5), que coexiste ao lado do direito geral.

Em tôdas essas definições, há visível concordância de vistas, expressa na invocação do mesmo elemento teórico-histórico, que explica a formação do jus civile como um processo resultante da particularização do direito comum em proveito da cidade, e essa analogia de conceitos está indicando que os seus autores deviam filiar-se a uma mesma corrente de opinião, em face da qual a conceituação dada àquele direito comum não podia extremar-se em conflitos inconciliáveis.

Assim não sucede, entretanto, graças principalmente às idéias de Ulpiano, conforme as expõem os redatores do Digesto, as quais criam, no conjunto doutrinário dos jura, visível des-

(3) D. 6 (1.1) "Jus civile est quod neque in totum a naturali vel gentium "recedit nec per omnia ei (iis?) servit; itaque quum aliquid addi"mus vel detrahimus juri communi, jus proprium, id est civile, effi"cimus".

(4) D. 9(1.1) “Omnes populi, qui legibus et moribus reguntur, partim "suo proprio, partim communi omnium hominum jure utuntur;... “quod quisque populus ipse sibi jus constituit, id ipsius proprium "civitatis est, vocaturque jus civile, quasi jus proprium ipsius civi"tatis" (Conf. Gaio, Inst. I, 1)

(5) D. 11 (1.1) "Jus pluribus modis dicitur: ... altero modo, quod "omnibus aut pluribus in quaque civitate utile est, ut est jus civile". 
conformidade com as demais opiniões transcritas, obrigando os exegetas a um trabalho de acomodação, que ora varia nos seus propósitos ou na escolha dos planos comparativos de referência, ora resulta em conclusões indeterminadas, de fundo ou de forma, que hão de perpetuar ad infinitum as perplexidades dos textos.

Voltemos, porém, às três classificações deduzíveis da sub-divisão do jus privatum:

1) Classificação de Ulpiano. As idéias de Ulpiano crescem, no caso, de significação, pois foi sôbre elas que Triboniano e seus assessores assentaram, na abertura do livro primeiro do Digesto, a sistemática introdutoria do direito, compreensiva das suas noções propedeuticas, inclusive as relativas à sua divisão fundamental, a cujo propósito ditou o jurisconsulto, segundo o fragmento transcrito, a doutrina da classificação tripartida do direito privado, que se compõe de preceitos do jus naturale, gentium e civile (6).

A expressão jus tripertitum dá o conceito categórico da tricotomia do direito, com a conseqüência, sob todos os aspectos invencível, de lhe parecerem distintos e diversos o jus naturale e o jus gentium.

Essa conclusão, aliás, nem precisaria ser deduzida, pois o texto caracteriza expressamente um e outro dêsses direitos, traçando-lhes o entendimento conceitual.

Jus naturale é aquele que a natureza ensinou a todos os animais, quod natura omnia animalia docuit (7). Jus gentium é aquele de que usam todos os povos, quo gentes humanae utuntur (8).

(6) D. $1 \S 2$ (1.1) "Privatum jus tripertitum est: collectum etenim est "ex naturalibus praeceptis aut gentium aut civilibus".

(7) Ulpiano, D. $1 \S 3$ (1.1)

(8) Ulpiano, D. $1 \S 4$ (.1) 
Não estivesse, já de si, clara a especificação diversificante do objeto de cada qual dêsses direitos, restaria ainda a distinção, que faz expressamente o fragmento, ao acentuar que é fácil entender como o jus gentium se diferencia do naturale, pois que êste é comum a todos os animais e aquele o é sòmente aos homens entre si, quod a naturale recedere facile intelligere licet, quia illud omnibus animalibus, hoc solis hominibus inter se commune sit (9).

Indo mais longe, exemplifica Ulpiano, no seguinte fragmento, o antagonismo (e não apenas a diferença), que separa os dois tipos de direito, ao relatar que a manumissão teve a sua orígem no jus gentium (quae res a jure gentium sumpsit), pois, como pelo direito natural, todos os homens nasceram livres (utpote quum jure naturali omnes liberi nascerentur,) não se conhecia a manumisão, desconhecida que era a escravidão (nec esset nota manumissio, quum servitus esset incognita); mas depois que surgiu, com o jus gentium, a escravidão, seguiu-se o benefício da manumissão (sed posteaquam jure gentium servitus invasit, secutum est beneficium manumissionis) (10).

Estão em jogo, nesse exemplo, que é, antes de tudo, a afirmação de um princípio teórico, os dois institutos, que caracterizam o máximo de contradição, no conflito das realidades humanas, e sobreexcedem o simples plano jurídico, para conceituar uma norma fundamental de ética: a liberdade e a escravidão (11). Pois bem. Segundo a derivação de preceitos, ex-

(9) Ulpiano, D. 1 § 4 (1.1)

(10) D. 4 (1.1) Êsse mesmo conceito, Ulpiano o repete em outra passagem, com a circunstância de correlacionar o jus naturale com o jus civile, a propósito do mesmo instituto da escravidão: "Quod attinet "ad jus civile, servi pro nullis habentur; non tamem et jure naturali, "quia, quod ad jus naturale attinet, omnes homines aequales sunt" D. $32(50.17)$

(11) Ao lado de Ulpiano, de igual Trifonino e Florentino sustentam as mesmas idéias, a propósito da liberdade e da escravidão, filiando-as identicamente ao jus naturale e ao jus gentium, para lhes realçar a imanente condição.

Segundo Trifonino, o senhor que, embora desobrigado, pagou 
posta por Ulpiano, a liberdade é uma decorrência lógica do direito natural, pois é êste que justifica o fato dos homens nascerem livres. Em sentido inverso, a escravidão tem a sua fonte no jus gentium, e sôbre êste se assenta a sua legitimidade, como prática usada pelos povos, em geral. 0 antagonismo dessas instituições há de refletir o antagonismo das origens ético-jurídicas, de que ambas decorrem, porquanto é de se entender que êsses dois tipos de direito não apenas se diversificam, mas até se negam, como a escravidão nega a liberdade.

o conflito aberto entre a escravidão e o direito natural é expressamente denunciado nas Institutas, nesse elucidativo passo: Jus autem gentium omni humano generi commune est. Nam usu exigente et humanis necessitatibus, gentes humanae quaedam sibi constituerunt; bella etenim orta sunt et captivitates secutae et servitudes, quae sunt naturali juri contrariae; jure enim naturali omnes homines ab initio liberi nascebantur (12).

A escravidão - escreve-se aí -, instituida pelo jus gentium, é contrária ao jus naturale.

Mas não só nessa diversidade de aspectos, divergem os dois direitos, entre os quais Ulpiano reparte o jus privatum. Divergem ainda, como vimos, pelo objeto, que lhe assinala 0 jurisconsulto, nos passos já transcritos (notas 7 e 8). Divergem, enfim, no característico peculiaríssimo, que dá Ulpiano ao direito natural, que, sendo aquele que a natureza ensina a

ao seu escravo, já manumitido, não poderá repetir, pois solveu uma obrigação natural; e se esta se entende que é natural, quanto a ser devida ou indevida em face da ação de repetição, é porque a liberdade decorre do direito natural e o direito do senhor sôbre o eseravo foi introduzido pelo direito das gentes ("... libertas naturali jure continetur et dominatio ex gentium jure introducta est" D. 64 (12.6).

De sua parte, Florentino escreve que a liberdade é uma faculdade da natureza ("libertas est naturalis facultas..."), enquanto a escravidão é uma constituição do direito das gentes, pela qual, contra a natureza, fica alguém sujeito ao domínio alheio ("servitus est constitutio juris gentium, qua quis dominio alieno contra naturam subjicitur") D. 4 \& 1 (1.5)

(12) I. $2(1.2)$ 
todos os animais, é também um direito comum aos homens, embora não seja exclusivo dêle (... jus istud non humani generis proprium, sed omnium animalium, quae in terra, quae in mari nascuntur, avium quoque, commune est (13).

Há razões evidentes para se perceber que o texto procura realçar as peculiaridades dêsse jus naturale, em ordem de distinguí-lo do jus gentium da definição de Gaio (14) e da exemplificação de Hermogeniano (15), a que aludiremos a seu tempo (v. nota 30 ).

Do jus naturale procede - segundo o texto de Ulpiano a união do macho e da femea, que nos chamamos matrimônio; dêle a procreação dos filhos; dêle a sua criação; pois vemos que também os demais animais, até as feras, se governam pelo conhecimento dêste direito (16).

A conceituação do jus naturale de Ulpiano é algo de tão extraordinário, no plano das idéias jurídicas do direito clássico, que a autenticidade dos textos invocados é posta em dúvida, como veremos logo mais.

Por ora acentuaremos, apenas, a integral diferenciação de conceitos, que informam a noção ulpianea do jus naturale e do jus gentium, para fixar o valor teórico da divisão tricotomica do jus privatum.

2) Classificação de Gaio. Enquanto no texto de Ulpiano o direito se triparte em direito próprio dos romanos (civile), direito comum a todos os povos (gentium) e direito comum aos homens e aos animais (naturale), Gaio no-lo apresenta dividido em duas partes: jus civile e jus gentium.

Se já lhe apreciamos o conceito dado ao direito civil (nota 4), vez é agora de completarmos o entendimento do texto parcialmente citado.

(13) D. 1 \& $3(1.1)$

(14) D. 9 (1.1) Conf. Gaio, Inst. I. 1

(15) D. 5 (1.1)

(16) D. $1 \S 3(1.1)$ “... hinc descendit maris atque feminae conjunctio, "quam nos matrimonium appellamus, hinc liberorum procreatio, "hinc educatio; videmus etenim cetera quoque animalia, feras etiam, "istius juris peritia censeri". 
Diz Gaio que todos os povos usam de dois direitos: o seu, que lhes é próprio, e outro, que é comum a todos os homens; e depois de definir o jus civile, adverte: mas aquele, que a razão natural estabelece entre todos os homens, é por todos igualmente observado e se chama jus gentium, como direito de que usam todos os povos (17).

Incontestàvelmente, a noção do jus gentium, que Gaio transmite nesse e em outros passos, é a que parece conservar a pureza das fontes legitimamente romanas, em consonância com a sistemática do pensamento clássico, fundado essencialmente no equilíbrio dos valores práticos e teóricos, nos escassos vôos, que se permitiam os seus juristas até às regiões da abstração ou da especulação filosófica.

Gaio, no pragmatismo das suas concepções, não vai além daquela invocação à ratio naturalis, que lhe é, na estruturação do direito, o elemento informativo das normas condizentes com a natureza humana, antes que com a natureza em si. 0 jus gentium se lhe apresenta como um direito positivo, consuetudinário ou escrito, comum aos povos, que se regem por leis ou costumes, direito de cunho universal, que coexiste em cada povo com o seu direito nacional (18). Era o que ocorria em Roma, onde, a lado do direito dos cives e das suas instituições particularistas, havia o direito dos peregrini e as instituições de caráter universal, que êle legitimava, como expressão de um direito comum e geral (19).

(17) 9 (1.1) "quod vero naturalis ratio inter omnes homines constituit, "id apud omnes peraeque custoditur, vocaturque jus gentium, quasi "quo jure omnes gentes utuntur".

(18) Von Mayr, "Historia del Derecho Romano": "El jus gentium era um sistema de derecho positivo de aplicação para os extranjeros, equiparable ao jus civile y correlativo a este... el jus gentium era el "canal" por el que entraban en el derecho romano las concepciones y las instituciones juridicas extranjeras" (liv. II, cap. V). Em sentido contrário diz Cathrein: "se necessita estar ciego para no ver que jus gentium no era de ninguna manera considerado como um derecho positivo, igual al jus civile" ("Filosof. del Derecho", cap. VI § 3)

(19) Cicero, De officiis, III, 17: "Itaque majores aliud gentium, aliud jus "civile voluerunt; quod civile non idem continuo gentium; quod autem "gentium, idem civile esse debet". 
Em outra passagem, Gaio reafirma o conceito da classificação dicotômica do direito e insiste na afirmação de ser a rátio naturalis o fundamento do direito geral, ao ensinar que "adquirimos o domínio de certas cousas pelo jus gentium, o qual, pela razão natural, se observa sempre entre todos os homens, e de outras pelo direito civil, isto é, pelo direito próprio de nossa cidade" (20).

0 paralelismo de idéias existente entre a ratio naturalis e 0 jus gentium, reitera-o o escritor em outras passagens, a propósito dos modos de aquisição da propriedade, diversos dos autorizados jure civile (21), como igualmente com relação às regras do jus personarum (22) e ainda a respeito das obrigaçōes (23).

(2) D. 1 (41.1) "Quarundam rerum dominium nancismur jure gentium, "quod ratione naturali inter omnes homines peraeque servatur, qua"rundam jure civile, id est, jure proprio civitatis nostrae".

(21) 0 que não é de ninguém, nullius, pertence ao que o ocupa, occupanti, pela razão natural, ratione naturali. As cousas tomadas ao inimigo, ex hostibus, tornam-se jure gentium dos que as tomam, capientium. 0 que por aluvião o rio acrescentou ao nosso campo, agro nostro, é por nós adquirido, nobis acquiritur, jure gentium. Sabino e Cassio julgam consultar melhor a razão natural, naturalem rationem, que o que se faz com matéria alheia, fique sendo do dono desta... D. 2; $5 \S 7 ; 6 \S 1 ; 6 \S 7$ (41.1); Gaio, Inst. II, 66; 69; 70; 79.

(22) Gaio, Inst. I: “... potestas juris gentium est..." (52); “... ex "eis, inter quos non est connubium, qui nascitur jure gentium ma"tris conditioni accedit..." (78); "... hoc (ex cive romano et pe"regrina, peregrinum nasci) jure gentium futurum erat..." (ibid); “... aliter vero contracto matrimonio, eum qui nascitur jure genti"um matris conditionem sequi..." (80); “... ex ancilla et libero "jure gentium servus nascitur..." (82); “... ne juris gentium re"gulam... lex aliqua... commutaverit..." (83); "...Divus Ha"drianus... restituit juris gentium regulam..." (84); “...Vespasi"anus... restituit juris gentium regulam..." (85); "... qui nasci"tur jure gentium matris conditionem sequitur..." (86); "...qui "nascitur liberum nasci, naturali ratione fit..." (89); "... quia "id naturali ratione conveniens est, ut is... alterius tutela regatur" (189).

(23) Gaio, Inst. III: “... ceterae (obligationes) juris gentium sunt, ita"que omnes homines sive cives romanos sive peregrinos valent" " $(93)$; “... quod genus obligationis juris gentium est" (132); "... ea societas... juris gentium est, itaque inter omnes homines "naturali ratione consistit" (154). 
O jus gentium da concepção gaiana é tìpicamente um direito positivo. Assim como há uma ratio civilis, que modifica (24), informa (25) e condiciona (26) o direito civil e a sua legislação, há uma ratio naturalis, que, sendo a fonte ou matriz do direito comum ao gênero humano, é a razão das instituições, que dêle derivam, e constituem o direito das gentes, como ressalta dessa passagem já assinalada: Sed ea quidem societas, de qua loquimur, id est, quae consensu contrahitur nudo, juris gentium est, itaque inter omnes homines naturali ratione consistit (27).

Essa ratio naturalis, ditada pela natureza, confunde-se, por um processo de equipolência vocabular, com o jus naturale e traça a sinonimia dêste com o jus gentium, na nomenclatura de Gaio (27a).

0 jus naturale de Gaio nada tem de comum com aquele que se inscreve no texto no Digesto, e se atribui a Ulpiano. E' o mesmo direito positivo, a que se filiam instituições jurídicas, como a traditio, a occupatio; que tem o seu característico no contraste aberto com o jus civile, seu par na divisão dicotomica do direito privado; que é idêntico a ratio naturalis, fundamento ostensivo do direito geral, do jus gentium, como ficou exposto linhas atrás.

(24) Gaio, Inst. I, 158; “. . quia civilis ratio civilia quidem jura corrum. "pere potest..."

(25) Gaio, Inst. II, 110: “... cum alioquin peregrini quidem ratione ci"vile prohibeantur capere hereditatem legataque..."

(26) Gaio, Inst. III, 154: “... capitis deminutione solvi societatem, quia "civili ratione capitis deminutio morti coaequatur".

(27) Gaio, Inst. III, 154.

(27a) A propósito do princípio da prevalência do direito geral sôbre o direito civil, a assinalada identidade entre o jus gentium e o jus naturale evidencia-se nessas duas passagens das Institutas de Gaio, I: "Animadvertere tamen debemus ne juris GENTIUM regulam, vel lex "aliqua vel quod legis vicem obtinet, aliquo casu commutaverit" (83); "Sed adgnationes quidem jus capitis deminutione perimitur, "cognationis vero jus eo modo non commutatur, quia civilis ratio ci"vilia quidem jura corrumpere potest, NATURALIA vero non "potest" (158). 
Veja-se a comprovação:

"65. Ergo ex his quae diximus apparet quaedam naturali jure alienari, qualia sunt ea quae traditione alienantur; quaedam civili, nam mancipationis et jure cessionis et usucapionis jus proprium est civium romanorum (28).

"66. Nec tamen ea tantum quae traditione nostra fiunt, naturali nobis ratione adquiruntur, sed etiam quae occupando ideo adepti erimus, quia antea nullius essent; qualia sunt omnia quae terra, mari, coelo capiuntur (29).

E' pois o jus gentium, segundo Gaio, o único ramo do direito privado diverso do jus civile, na acepção de direito comum a todos os povos e a todos os homens, o mais antigo direito, que nasceu com o próprio gênero humano (30).

3) Classificação de Paulo. Segundo o fragmento inserto no Digesto, Paulo expõe que o direito se entende por vários modos; em um dêles, quando se chama direito aquele que é sempre equitativo e bom, como é o direito natural (uno modo quum $i d$, quod semper aequum ac bonum est, jus dicitur, ut est ius naturale); em outro, o que em cada cidade é útil a todos ou à maior parte, como é o direito civil (31), afora outras acepções, de sentido particularista.

(28) Gaio, Inst. II.

(29) Gaio, ibid.

(30) Gaio, D. 1 (41.1) "... et quia antiquius jus gentium cum ipso ge"nere humano proditus est..."

Há que se notar que, à maneira de Ulpiano, na sua definição de jus naturale, Hermogeniano - D. 5 (1.1) empresta ao jus gentium uma conceituação compreensiva de elementos extra-jurídicos, inclusive a divisão dos povos, a fundação dos reinos, a construção dos edifícios, ao lado das verdadeiras instituições de direito, como os contratos e as obrigações, não sem distinguir destas aquelas que a jure civili introductae sunt, à maneira de Gaio. Bem de ver, entretanto, que afora essa idêntica invocação de princípios rudimentares da existência (ou animal, em Ulpiano, como a união dos sexos, ou social, em Hermogeniano, como a delimitação dos campos), nada de comum tem o jus gentium dêste com o jus naturale daquele.

(31) D. 11 (1.1) Albertario ("Studi", V vol. XI) filia o texto transcrito ao Fragmentum Dositheanum, para por em realce o objetivo dos 
Assim, para Paulo, o direito, na sua principal compreensão, se biparte em jus naturale e jus civile (32), e de certa forma essa sub-divisão merece logar diverso da que se dá à de Ulpiano e de Gaio, embora se relacione com a dêste pelo critério da divisão dicotomica e com a daquele pelo conteúdo ideativo emprestado ao jus naturale.

Vale a classificação, entretanto, pela sua significação didática e pela primazia, que concede ao jus naturale, ao valorizá-lo com os atributos teóricos, que informam o conceito original do próprio direito, menos como direito positivo universal, direito cle todos os povos, do que como expressão conceitual do fenômeno jurídico, na sua formulação abstrata.

compiladores bisantinos, em distinguir o jus naturale do jus gentium. Assim, o semper foi introduzido para reafirmar o novo sentido filosófico de um direito perpétuo, no tempo, noção essa que Justiniano repete em passagem original das suas Institutas: "naturalia jura, "divina quadam providentia constituta, semper firma atque immu"tabilia permanent" - I. 11 (1.2).

E' o seguinte o Frag. Dosith, segundo a leitura de Lachmann (in "Textes". Girard, p. 505):

"Omne jus aut civile appellatur aut naturale. Naturale dicitur "etiam jus gentium; ab eo nominatum, quod omnes gentes similiter "eo sunt usae; quod enim bonum et aequum est, omnium utilitati "convenit. Sed jus civile proprium est civium romanorum, ab eo "dictum quod nostra civitas eo... utitur. Sed quidam hoc esse prae"dicant, quos omnibus civibus peculiariter aut majori parti expedit". Releia-se o texto de Paulo, no Digesto, e observe-se a identidade dêste com aquêle:

"Jus pluribus modis dicitur: uno modo, cum id quod (semper) "aequum ac bonum est jus dicitur, ut est jus naturale. Altero modo, "quod omnibus aut pluribus in quaque civitate utile est, ut est jus "civile".

Teriam assim os compiladores omitido a referência ao jus gentium e para relêvo do jus naturale introduzido a noção da perpetuidade (semper) em logar da noção de utilidade (omnium utilitati convenit), deixando assimetricaa antitese da proposição de Paulo, que assim se corrigiria: "jus (gentium vel naturale) omnium utilitati "conveniens; jus (civile) omnibus vel pluribus in quaque civitate "conveniens".

(32) Semelhantemente, Modestino, ao tratar da cognação, afirma que, em essência, ela se entende entre os romanos de dois modos, bifariam, porque certas cognações se efetivam jure civili, outras jure naturali; e algumas vêzes a cognação se realiza utroque jure concurrente, et naturali et civili. D. $4 \S 2(38.10)$.

Tratando da aquisição do domínio, o mesmo escritor alude às cousas, que se adquirem civiliter e as que se adquirem naturaliter, sicut est possessio - D. 52 (41.1), à maneira aliás de Ulpiano D. $3 \S 15(10.4) ;$ D. $1 \S 9$ (43.16). 
$\mathrm{Na}$ verdade, se o direito (jus) é a arte do bom e equitativo (boni et aequi), como noção fundamental derivada da justiça (jus est a justitia appelatum), segundo Celso e Ulpiano (33), o jus naturale de Paulo copia-lhe o conceito ideológico, pois êle é identicamente aequum ac bonum.

Dando assim o máximo relêvo à compreensão do direito natural, nem por isso Paulo desconhece o jus gentium, como de igual não desconhecia Gaio, à sua época, o jus naturale, circunstancia que não obsta admitissem um e outro a divisão apenas dúplice do jus privatum.

E' verdade que as idéias de Paulo, a êsse respeito, não exibem a mesma segurança de orientação, que se encontra em Gaio (34), e tudo nos levaria a relacioná-las de preferência com o pensamento de Ulpiano (35), conforme o Digesto o apresenta, não fôra o receio de colaborar na generalização dos pressupostos da doutrina justineanea, preocupada em acentuar o conceitualismo naturalista do direito, herdado da filosofia grega e valorizado pelas idéias cristãs, dominantes no mundo bisantino (36). Como veremos, a seu turno, os compiladores do Di-

(33) D. 1 (1.1).

(34) Advirta-se que a crítica tem em vista a possibilidade, que se abriu aos intérpretes, de estudarem as opiniões de Gaio na sua obra original, a salvo portanto das modificações introduzidas pelos compiladores post-clássicos na versão do Digesto.

(35) Ulpiano e Paulo viveram na mesma época, foram ambos assessores de Papiniano (202 - 212) e comentadores da sua obra, e, de igual, foram prefeitos do pretório sob Alexandre Severo (222 - 228).

(36) Bonfante precisa que os juristas clássicos estavam informados do pensamento grego, especialmente das duas fontes que, do ponto de vista especulativo e ético, aparecem como as mais altas diretrizes do saber e da conduta: a escola aristotélica e a escola stoica, enquanto que as doutrinas platônicas e neoplatônicas influenciaram notòriamente a elaboração jurídica da época romano-helênica ("Hist. del Der. Rom.", I, cap. XXI, n. 2). Para Albertario essa influência é principalmente a da escola pitagórica, a que se ajunta "el pensiero cristiano", na formulação das compilações justineaneas ("Studi di Rom.", V, n. XI). Henri Rommen esclarece que a jurisprudência clássica impregnou-se da lição dos stoicos e, por seu intermédio, dos ensinamentos de Heraclito, de Platão, de Aristoteles e dos sofistas moderados ("Le Droit Naturel", cap. I, n. 3). 
gesto deram franca passagem às noções favoráveis à preeminência do jus naturale, e os indícios dessa preocupação provam que êles foram ao extremo das interpolações abertas, como se deduz da análise sutil dos intérpretes (37) ou da superposição dos textos originais com as aqueles transcritos nos fragmentos do Corpus Juris, conforme veremos adiante.

$\mathrm{Na}$ antitese da doutrina de Paulo, ao jus civile opõe-se indistintamente o jus gentium, o jus naturale, a aequitas ou a ratio naturalis, sob noções nem sempre idênticas ou precisas, mas em qualquer caso assemelhadas.

Assim, quando, por direito civil, jure civile, faltem os filhos, que deixaram de ser heredes sui, por via da capitis deminutio, o pretor, por equidade, propter aequitatem, pode extinguir eorum capitis deminutionem (38).

Quando falte a actio pluviae arcendae, opina caber contra o vizinho a actio utilis ou o interdictus, para reparar o dique in agro ejus: isto é o que sugere a equidade, ainda que careçamos de direito (positivo ou civil), haec aequitas suggerit, etsi jure defficiamur (39) .

Tratando da exceptio doli mali, esclarece que o pretor a instituiu para que a ninguém aproveite contra naturalem aequitatem o seu próprio dolo, per occasionem juris civilis (40).

A actio in rem compete a quem adquiriu o domínio aut jure gentium aut jure civili (41).

(37) 0 texto de Paulo - D. $14 \S 2(23.2)$ é por vários autores apontado como interpolado pelos compiladores bisantinos para êsse fim: "Un"de nec vulgo quesitam filiam pater naturalis potest uxorem ducere, "quoniam in contrahendis matrimoniis (naturale jus et) pudor ins"piciendus est; contra pudorem est autem filiam uxorem suam du"cere". Não se tratasse de uma intercalação apressada das palavras naturale jus et, e o último período não aludiria sòmente ao pudor, como está escrito.

(38) D. $6 \S 1(37.1)$

(39) D. $2 \S 5(49.3)$

(40) D. 1 \& $1(44.4)$

(41) D. $23(6.1)$ 
A razão natural, quase como uma lei tácita, assegura aos descendentes a herança dos ascendentes, ratio naturalis, quasi lex quaedam tacita, liberis parentum hereditatem addiceret; por causa disso, também em direito civil, deu-se-lhes o nome de herdeiros seus, propter quod et in jure civili suorum heredum nomen iis indictum est (42).

Se cada qual pode vender as suas cousas, nula porém é a venda daquelas, earum nula venditio est, as quais natura vel gentium vel mores civitatis retiraram do comércio (43).

$\mathrm{Na}$ sua própria intercorrelação, a noção do jus naturale e do jus gentium mantém essa mesma indeterminada assemelhação, na doutrina de Paulo.

A locatio conductio, como seja uma instituição natural e de todos os povos, cum naturalis sit et omnium gentium, contrae-se pelo consentimento e não por palavras, como a emptio venditio (44), e esta, de sua vez, é do direito das gentes, est autem emptio juris gentium (45).

Aquele que é obrigado a dar pelo jus gentium, deve por natureza, is natura debet, quem jure gentium dare oportet (46), e na esteira de outras citações, vemos o jus gentium ser invocado para impedir a alienação das praias, litora quae fundo vendito conjuncta sunt... non computantur, porque não são de ninguém, quia nullius sunt, pois pelo direito das gentes estão ao dispor de todos, sed jure gentium omnibus vacant (47); vemo-lo ainda proclamado como fundamento do casamento incestuoso, jure gentium incestum committit quem casar-se com mulher no grau dos ascendentes ou descendentes, qui ex gradu adscendentium vel descendentium uxorem duxerit (48), ainda que em matéria de casamento anote-se ser de observar-se o di-

(42) D. $7(48.20)$

(43) D. 34 \& $1(18.1)$

(44) D. $1(19.2)$

(45) D. 1 § $2(18.1)$

(46) D. $84 \S 1(50.17)$

(47) D. $51(18.1)$

(48) D. $68(23.2)$ 
reito natural, in contrahendis matrimoniis naturale jus... inspiciendum est (nota 37 ).

Não se pode negar que os compiladores bizantinos tiveram a preocupação de realçar a importância do jus naturale, no plano das noções teóricas compendiadas, tanto mais que a concepção naturalista do direito afinava de perto com as idéias da filosofia cristã, e essa técnica, no processo da ordenação do Corpus Juris, não podia deixar de contribuir para agravar a imprecisão de conceitos, em que vacilavam os juristas clássicos, em suas obras originais.

Acresce que a perspicácia dos modernos estudiosos tem posto em dúvida a autenticidade de textos decisivos do Digesto, no empenho de distinguir o pensamento do direito clássico das alterações decorrentes da influência heleno-bizantina, nem sempre bem assimiladas ou compreendidas pelos juristas da decadência (49).

Manda a lógica que se entendessem idênticas as noções dò jus naturale e do jus gentium, pois que são ambos expressão do mesmo jus commune, como ensina Ulpiano (50), e têm como fonte a mesma naturalis ratio, conforme vimos em tantos textos citados.

Mas o próprio Ulpiano expẽe doutrina diversa, e a análise das razões, que são invocadas para a explicação do fato, apresenta-se tocada de invencíveis dificuldades, fundadas inicialmente na ausência das obras originais do escritor, em que êste tivesse versado o assunto - as suas Institutiones ou os libri ad Sabinum - que se perderam na maior parte, circunstância que deixa sem comprovação os fragmentos do Digesto, em fa-

(49) Albertario, op. cit. n. 4: "Dove le fonti giustinianee definiscono il jus naturale come nozione diversa dal jus gentium, sono visibilmente alterate: dove affermano che la schiavitu é juris gentium ma contra naturam, e proclamano che tutti gli uomini sono jure naturali liberi - aequales sono pure alterate indiscutibilmente. Il jus naturale, in somma, si differenzia dal jus gentium soltanto nell'etá posteriore alla classica e si colloca, cosi separato dal jus gentium, nelle legislazione giustinianea accanto e contro al jus civile".

(50) D. 6 (1.1) 
vor ou desfavor da sua genuidade. Há de pairar sempre uma interrogação sôbre êsse obscuro capítulo do direito romano, a mesma que entenebrece a compreensão das Institutas da coleção justinianea, nos passos que se referem exatamente a êsse assunto, e onde, por motivos não esclarecidos, os seus redatores perpetuaram, num só corpo de doutrina, as contradições teórico-didáticas, que no Digesto correm por conta dos juristas clássicos, fragmentariamente citados.

A exposição das Institutas é, na verdade, patentemente defeituosa.

No Cap. De Just. et Jure assenta que o jus privatum é tripartido, constituindo-se de preceitos do jus naturale, gentium e civile (51). No Cap. seguinte, De Jure Nat. Gent. et Civile, contradiz-se, ao declarar que o direito se divide assim: civile vel gentium (52).

Nesse mesmo capítulo articula o conceito de jus naturale, conforme a lição de Ulpiano (53) e o do jus gentium e do jus civile, conforme a de Paulo (54). Adita, após, um novo conceito de jus gentium (55), que recorda o de Ulpiano (56), com o visível intuito de estabelecer a antinomia entre o jus gentium e o jus naturale, a propósito da liberdade e da escravidão (57), dando assim curso à mesma idéia, que reedita, em seguida (58), já agora em cópia do fragmento de Ulpiano (59). Logo adiante,

(51) I. $4(1.1)$

(52) I. 1 (1.2)

(53) “... est quod natura omnia animalia docuit..." I. princ. (1.2)

(54) I. 1 (1.2)

(55) “... omni humano generi commune est..." I. 2 (1.2)

(56) “... hominibus inter se commune sit..." D. 1 § 4 (1.1)

(57) “... gentes humanae quaedam sibi constituerunt: ... bella... ca"ptivitates... et servitutes, quae sunt juri naturali contrariae: jure "enim naturali ab initio omnes homines liberi nascebantur". I. 2 (1.2)

(58) “... cum jure naturali omnes liberi nascerentur... posteaquam ju"re gentium servitus invasit... secutum est beneficium manumis"sionis". I. princ. (1.5)

(59) D. 4 (1.1) 
denunciando os pressupostos doutrinários do pensamento dominante no meio e no momento, sob a influência das preocupações religiosas do cristianismo, em plena ascensão vitoriosa, renova outra definição de direito natural $(60)$, agora identificada com a noção do jus gentium (61), para, no ensejo, declará-lo constituído pela Divina Providência, donde os característicos da sua perenidade e imutabilidade (62). E, enfim, enredando-se na complexidade do tema, de que mal se assenhoreara, desce à simples equiparação de um e outro dêsses direitos, pelo processo primário de sua sinonimização vocabular (63).

0 emaranhado dessas noções trai a insegurança da doutrina compendiada, e essa circunstância contribui para fortalecer a convicção de que muitas das idéias referentes ao jus naturale foram introduzidas nos fragmentos do Digesto pela mão dos compiladores bizantinos, com violência ao sistema de suas concepções originais e conseqüente desharmonia do seu conteúdo doutrinário (64).

(60) "... naturalia jura, quae apud omnes gentes peraeque servantur..." I. $11(1.2)$

(61) „... apud omnes peraeque custoditur, vocaturque jus gentium..." D. $9(1.1)$

(62) “... naturalia jura... divina quadam providentia constituta, semper firma atque immutabilia permanent." I. 11 (1.2).

Vale, a propósito dêsse passo, recordar Bonfante: "La filosofia pagana havia sido destronada por la teologia cristiana y nadie mostro una tan viva repugnancia por las concepciones da la filosofia, que tenian un sabor de paganismo, como el emperador Justiniano, que, precisamente, fue quien ordeno la clausura de las escuelas filosoficas de Atenas" (Hist. del Der. Rom., I, cap. XXI).

(63) “... quarundam enim rerum dominium nanciscimur jure naturali, "quod, sicut diximus, appellatur jus gentium..." I. 11 (2.1)

"... tamen recte dicitur et jure gentium, id est, jure naturali, "id effici". I. 41 (2.1)

(64) Perozzi “Inst. di Dir. Rom"., I, Introd. cap. III) anota, entre outras, as seguintes interpolações, expressas pelas palavras, que figuram entre parentesis:

Trifonino, D. 31 (16.3): "Si tantum (naturale et) gentium jus intuemur..."

Trifonino, D. 64 (12.6): “... quia naturale adgnovit debitum: "(ut enim libertas naturali jure continetur et dominatio et gentium "jure introducta est, ita debiti vel non debiti ratio in condictione na"turaliter intelligenda est".

Ulpiano, 6 (1.1): "jus civile est quod neque in totum a (natu- 
Se essa afirmativa funda-se nas sutilezas de uma exegese, que pode ser posta em dúvida, há entretanto outros elementos comprobatórios da alteração do pensamento original dos escritores clássicos, como os que decorrem do confronto do texto das Institutas de Gaio conn o do Digesto e das Institutas de Justiniano, ou dêstes, entre si.

Senão, vejamos :

I. Gaio, II, 69 :

Ea quoque, quae ex hostibus capiuntur, NATURALI RATIONE nostra fiunt.

D. Gaio, $5 \S 7$ (41.1) :

Item quae ex hostibus capiuntur, JURE GENTIUM statim capientium fiunt.

I. $17(2.1)$ :

Item ea quae ex hostibus capimus, JURE GENTIUM statim nostra fiunt.

A substituição impôs-se, no caso, porque na doutrina dos bizantinos os prisioneiros eram submetidos à escravidão, contra naturam - D. 4 (1.5); I. 2(1.2), e não ratione naturali. Sendo a servitus uma constitutio juris gentium, contrária ao jus naturale, repugnava-lhes a concepção do texto gaiano.

"rali vel) gentium recedit neque per omnia ei servit; (itaque cum

"aliquid addimus vel detrahimus juri communi, jus proprium, id est

"civile, efficimus)".

Paulo, D. 34 \& 1 (18.1): “... quas vero (natura vel) gentium "jus vel mores civitatis commercio exuerunt". tas...".

Florentino, D. 4 princ. (1.5): "libertas est (naturalis) facul-

Florentino, D. $4 \S 1$ (1.5): “.. qua quis dominio alieno (contra "naturam) subjicitur...".

Ulpiano, D. 4 (1.1): “... manumissus liberatur potestate, "(quae res a jure gentium originem sumpsit, utpote cum jure natu"rali omnes liberi nascerentur... etc. etc... qui desierant esse ser"vi)".

Ulpiano, D. 32 (50.17): “(quod attinet ad jus civile) servi pro "nullis habentur; (non tamen et jure naturali, quia, quod ad jus

"naturale attinet, omnes homines aequales sunt)". 
Outro cotejo elucidativo é o do texto sôbre a aquisição do domínio das cousas e, de igual, sôbre qual fôsse o mais antigo direito.

Anotemos:

D. Gaio, 1(41.1):

... quarumdam rerum dominium nanciscimur JURE GENTIUM, quod ratione naturali inter omnes homines peraeque servatur...

\section{I. $11(2.1)$ :}

... quarundam enim rerum dominium nanciscimur JURE NATURALI, quod sicut diximus appellatur jus gentium...

\section{Gaio, ibid. :}

Et quia antiquius JUS GENTIUM cum ipso genere humano proditum est, opus est ut de hoc prius referendum sit.

\section{I. ibid. :}

Commodius est itaque a vetustiore jus incipere. Palam est autem vetustius esse NATURALE JUS, quod cum ipso genere humano rerum natura prodidit.

E' visível o intuito de acomodação do texto gaiano aos propósitos doutrinários do pensamento dos compiladores: 1) o direito deduzido da ratio naturalis não é o jus gentium, mas o jus naturale, que também se chama... jus gentium; 2) o direito mais antigo, que nasceu com o próprio gênero humano, não é o jus gentium, mas o jus naturale, que a natureza das cousas gerou com o gênero humano.

Fundados nos pressupostos de uma propositada alteração da verdadeira doutrina clássica, escritores de maior valia carregam à conta dos redatores do Corpus Juris a divisão tripartida do direito, feita para enobrecer o jus naturale, (65) direi-

(65) Henri Rommen testemunha a ascendência do direito natural a essa época: "Même aprés la restauration de la "souverainité imperiale" á l'epoque du Bas-Empire (Justinien), le droit naturel reste pour le legislateur la norme veritable, premiére et supreme, la régle fundamentale des relations humanes" ("Le Droit Naturel", p. 50). 
to diverso do jus gentium, ensinado pela natureza aos homens e aos animais, o qual, fugindo aos contornos especulativos de sua teorização, se entredemonstra sob a forma de preceitos integrantes do jus privatum, do direito positivo, na conceituação do texto ulpianeo.

E' inegável que, sob inúmeros aspectos, o jus naturale e o jus gentium se confundem, no plano especulativo, e as fontes romanas testemunham essa indeterminação de conceitos, no processo de filiação das normas jurídicas às matrizes, de que elas se originam, sempre que não provenham do jus civile.

Assim, para que os dois direitos se distinguissem, e justificassem a tricotomia duvidosa, três princípios foram erigidos e levados à responsabilidade da influência post-clássica, obediente às idéias dos filósofos gregos e aos novos princípios cristãos, que iriam ser abraçados pelos escolásticos (66) : a noção de um direito natural, próprio a todos os seres vivos (67), a idéia da imutabilidade dos direitos naturais, decorrentes da inteligência divina (68) e o princípio da igualdade de todos os homens, diante do direito natural (69).

Por via dêste último postulado, o jus naturale contradiz o jus gentium (70). Por efeito do segundo, essa contradição se acentua, em face da transitoriedade do direito positivo (71). Enfim, por via do primeiro, o jus naturale diverge do jus gen-

(66) Sôbre essa influência, ver Henri Rommen (op. cit., p. 50-51).

(67) Ulpiano, D. $1 \S 3$ (1.1): "Jus naturale eșt quod natura omnia ani"malia docuit".

(68) I. 11 (1.2) "Naturalia jura... divina quadam providencia constitu"ta, semper firma atque immutabilia permanent".

(69) Ulpiano, D. 4 (1.1); 32 (50-17) "jure naturali omnes liberi nasce"rentur..."; "quod ad jus naturale attinet, omnes homines aequales "sunt".

(70) Florentino, D. $4 \S 1$ (1.5); I. 2 (1.2): "Servitus est constitutio ju-" "ris gentium..."; "servitutes... sunt juri naturali contrariae...".

(71) I. 11 (1.2): "Ea (jura) quae ipsa sibi quaeque civitas constituit "saepe mutari solent..." 
tium, direito deduzido da natureza do homem, para alcançar o conceito de um direito ideal, fundado na ordo rerum ou na rerum natura, sobreexcedente da natureza humana (72).

A idéia de uma lei natural, que sujeita todos os seres vivos, foi conhecida dos filósofos gregos e dos retóricos romanos: era menos uma noção jurídica que um conceito especulativo (73), e nêle insistiram muitos partidários do direito natural (74), sendo de notar-se que São Tomaz de Aquino funda diretamente no questionado fragmento de Ulpiano sôbre o jus naturale ("ut jurisconsultus dicit”) a sua doutrina: Absolute autem appreendere aliquid: non solum convenit homini, sed etiam aliis animalibus. Et ideo jus quod dicitur naturale... commune est nobis et aliis animalibus (75).

Certo, a conceituação ulpianea do jus naturale, incluida no texto do Corpus Juris, defensável, para uns, como idéia ético-jurídica (76), combatida por outros, ou pela impropriedade dos seus termos, como faz Savigny (77) ou pela infelicidade da expressão, conforme diz Alexandre Correia (78), ainda que ambos a justifiquem, significa para Albertario uma stoltezza (79) e para Perozzi um concetto pueril ed inutile (80).

(72) Ulpiano, D. $1 \S 3(1.1)$; 4 (1.1): "Jus naturale... omnium animalium commune est"; "jus gentium... solis hominibus commune "sit".

(73) Cicero, De Rep. 3,11, 19: "Pythagoras et Empedocles unam omnium "animantium conditionem juris esse denuntiant". Idem, De Off. 1, "17, 54: "Nam cum sit hoc natura commune animatium, ut habeant "libidinem procreandi, prima societas in ipso conjungio est, proxima "in liberis, deinde una domus, communia omnia..." Séneca, De "Clem. I, 16,2: "commune jus animantium..."

(74) Grocio alude aos vestígios de razão, que há nos animais: "quando "brutis animantibus justitia tribuitur, id fit improprie ex quadam "in ipsis umbra rationis atque vestigio" (De jure bel. ac pac. I, cap. $1 \S 11)$. Ver em Giorgio del Vecchio a sua exposição sôbre a justiça entre os animais ("La Justicia", I)

(75) Summa, IIa. IIae. qu. 57 art. 3.

(76) Jean Dabim, “Theor. Gen. du Droit", n. 209: "Aucune difference n'a jamais até établie entre de droit naturel inter-individuel e la morale inter-individuel, entre le droit naturel de l'union des sexes, de la generation et de l'education e la morale familiale..."

(77) "Traité de Droit Rom.", I, apend.

(78) “Dir. Rom.", p. 10

(79) loc. cit. n. 2

(80) op. cit. cap. III, § 8, p. 24 